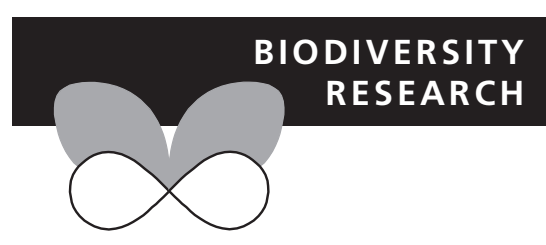

\title{
Species-people correlations and the need to account for survey effort in biodiversity analyses
}

\author{
A. Márcia Barbosa ${ }^{1,2 *}$, Marco Pautasso $^{3}$ and Diogo Figueiredo ${ }^{1}$
}

${ }^{1}$ Cátedra 'Rui Nabeiro/Delta Cafés' -

Biodiversidade, Centro de Investigação em

Biodiversidade e Recursos Genéticos

(CIBIO), Universidade de Évora, Évora

7004-516, Portugal, ${ }^{2}$ Division of Biology,

Imperial College London, Silwood Park

Campus, Ascot, SL5 7PY, UK, ${ }^{3}$ Centre

d'Ecologie Fonctionnelle et Evolutive (CEFE),

CNRS, Montpellier, 34293 France

${ }^{*}$ Correspondence: A. Márcia Barbosa, 'Rui Nabeiro' Biodiversity Chair, Centro de Investigação em Biodiversidade e Recursos Genéticos (CIBIO) - University of Évora, 7004-516 Évora, Portugal.

E-mail: barbosa@uevora.pt

\section{ABSTRACT}

Aim Positive regional correlations between biodiversity and human population have been detected for several taxonomic groups and geographical regions. Such correlations could have important conservation implications and have been mainly attributed to ecological factors, with little testing for an artefactual explanation: more populated regions may show higher biodiversity because they are more thoroughly surveyed. We tested the hypothesis that the correlation between people and herptile diversity in Europe is influenced by survey effort.

\section{Location Europe.}

Methods Although no explicit survey effort information is available in our dataset, we can divide Europe into three nested regions that were subjected to different levels of survey coverage. We compared species-people correlations among these regions, both with and without controlling for landscape diversity and latitude (a wrapper for energy-related variables whose individual effects on species richness were weaker). We also tested for relationships between human population and the distributions of single species.

Results Both mean species richness and human population density increased as we restricted the analyses towards better-surveyed regions. Whether or not accounting for ecological factors, the positive relationship between species richness and human density was significant at the lower survey coverage levels, but faded as the analysis focused on better-surveyed regions and disappeared in the best-surveyed level. Single-species analyses revealed identical patterns, for both human-avoiding and human-adapted species.

Main conclusions Our findings suggest an artefactual origin for the herptilepeople correlation in Europe. More importantly, they highlight the importance of addressing sampling bias in biodiversity analyses, which may be possible even when survey effort is not recorded. We also emphasize the utility of noting survey effort along with biodiversity records and the need for better surveys of biodiversity in less populated areas. An adequate identification of conservation conflicts requires more rigorous assessments of the effects of survey effort on biodiversity data.

\section{Keywords}

Amphibians, artefacts, biodiversity patterns, confounding effects, reptiles, sampling effort, species-people correlation, spurious relationships.

\section{INTRODUCTION}

Positive, regional correlations between human population density and species richness have been recorded for various taxonomic groups and geographical regions (e.g. Balmford et al., 2001; Araújo, 2003; Pautasso, 2007; Moreno-Rueda \& Pizarro, 2009; Marini et al., 2012). If not an artefact, such a large-scale coincidence of high numbers of species and people could have important conservation consequences, because of the local negative effects of high human population density on 
biodiversity, through habitat fragmentation, degradation and loss, water, air and soil pollution, and other effects of urbanization (e.g. Ellis et al., 2012; Herrmann et al., 2012; Vačkár et al., 2012; Murrieta-Galindo et al., 2013). If biodiversity-rich regions are disproportionately inhabited, local human impacts on species will tend to be magnified, other things being equal (Luck et al., 2004; Barbosa et al., 2010a; Johnson et al., 2013; McCauley et al., 2013). At the same time, if urbanized landscapes still show areas with high species richness, there are better opportunities for biodiversity education and natural recreation of town dwellers (Davies et al., 2009; Ribeiro et al., 2010; Pautasso et al., 2011).

Some possible mechanisms have been invoked to explain positive species-people correlations, namely that the distributions of both biodiversity and human beings tend to match patterns of environmental energy, primary productivity and habitat diversity (e.g. Fjeldså, 2007; Moreno-Rueda \& Pizarro, 2007). There has been little testing and evidence for an artefactual explanation: more populated regions may have more species records because they are better and more often surveyed than remote, less accessible areas (e.g. Pecher et al., 2010; Ficetola et al., 2013). The possibility of this artefact affecting the results of biodiversity analyses has seldom been taken into account, mainly because data on the spatial distribution and intensity of survey effort are rarely available (Araújo, 2003; Luck et al., 2010). But when it has been accounted for, survey effort has often shown a significant effect on the correlations of species diversity with environmental variables (e.g. Barbosa et al., 2005; Ribas et al., 2007; Fontaneto et al., 2012) and, in particular, with human population (e.g. Cantarello et al., 2010; Barbosa et al., 2010b; see, however, Kühn et al., 2004; Pautasso \& McKinney, 2007).

At a European scale, positive regional species-people correlations have been documented for plants and for several groups of terrestrial vertebrates (Araújo, 2003), although without accounting for survey effort. In a previous analysis for similar taxonomic groups in sub-Saharan Africa, Balmford et al. (2001) found a stronger species-people correlation for better-surveyed groups and interpreted this as an indication that the correlation was not biased by survey effort (see also Araújo, 2003). However, this may not be a matter of better-surveyed taxa, but rather better-surveyed regions. Better-surveyed taxa may still suffer from survey bias towards more populated areas; it is in regions subjected to broader and more evenly distributed survey coverage that we should check whether the species-people correlation holds.

Spatial autocorrelation is another issue to take into account. Both species richness and human population exhibit autocorrelation in space, which may affect parameter estimates and inflate type I errors when looking for relationships between them (Diniz-Filho et al., 2003; Dormann et al., 2007). Spatial autocorrelation has been controlled for in analyses of regional species-people correlations of invertebrate groups in European countries, although without information about variation in sampling effort (Pautasso \& Fontaneto, 2008; Steck \& Pautasso, 2008).
Here, we test the hypothesis that the correlation of people and biodiversity in Europe is determined by the distribution of survey effort, using amphibians and reptiles (herein referred to as 'herptiles') as a case study. Herptiles have been found to be positively associated with human population density in south-eastern Spain (Moreno-Rueda \& Pizarro, 2007), in Europe (Araújo, 2003) and in sub-Saharan Africa (Balmford et al., 2001). A coexistence of high herptile diversity and dense human settlements across Europe could be particularly worrying from a conservation biogeography perspective (Araújo, 2003) and would require increasing efforts for wetland habitat restoration in urbanized landscapes (Scheffers \& Paszkowski, 2013). Herptiles face increasing conservation threats (Stuart et al., 2004; Sinervo et al., 2010) and are nevertheless neglected compared with other vertebrates (Bombi et al., 2012), besides being the object of negative attitudes from people (Ceríaco, 2012). The broad-scale species-people correlation could be particularly important for amphibians, as both people and amphibians depend on the availability of freshwater (e.g. Kummu et al., 2011).

The herptile distribution data from Europe make it possible to address the effect of survey effort: the European herpetological atlas covers the whole European continent; the western half of the continent was better surveyed than the eastern half (Gasc et al., 1997); and eight Western European countries had their own herpetological atlases published before the European atlas (Societas Europaea Herpetologica, 2012), which means they were particularly well surveyed. We are thus able to compare the strength and significance of the species-people correlation among increasingly better surveyed regions, with three nested levels of general survey coverage. If the species-people correlation weakens as we restrict the focus to more thoroughly surveyed regions, then this correlation may indeed be determined by the distribution of survey effort.

We also test the relationships between single species' distributions and human population density. Some species may have an actual association with humans (because they profit from man-made infrastructures such as stone constructions and water storage), while others may prefer more pristine habitats, and others may be roughly indifferent to human proximity as long as their environmental requirements are met. If single species (even human-avoiding ones) also show positive correlations with human population density across Europe, and these correlations disappear as we restrict the analysis to better-surveyed regions, then it can be argued that species-people correlations are indeed an artefact caused by biased survey effort.

\section{METHODS}

\section{Species data and spatial units}

Species distribution data were taken from the European atlas of amphibians and reptiles (Gasc et al., 1997). For the sake of coherence with the distribution data, Gasc et al. (1997) 
was the general nomenclatural source for this study, although some species have later experienced name changes or genus reassignments. The general study area was Europe as reflected in this atlas, with the Universal Transverse Mercator (UTM) $50 \mathrm{~km} \times 50 \mathrm{~km}$ grid cells as spatial units of analysis (Fig. 1). Macaronesia (Azores, Madeira and Canary Islands) was not included in the atlas. We excluded also Iceland because it has no native amphibians or reptiles for reasons that cannot be related to the species-people correlation.

Political boundaries and UTM cell maps were downloaded from the EDIT Geoplatform (Sastre et al., 2009). Maps were processed with GRASS (Geographic Resources Analysis Support System; GRASS Development Team, 2010) through the graphical interface of QUANTUM GIS 1.5 (Quantum GIS Development Team, 2010). All other data management and analyses were carried out in R 2.13 ( $\mathrm{R}$ Development Core Team, 2012) except where otherwise stated.

\section{Survey effort}

Unlike some previous authors (e.g. Ribas et al., 2007; Barbosa et al., 2010b; Fontaneto et al., 2012), and as Araújo (2003) pointed out, we do not have explicit data on the number of visits or records for each UTM cell with which to assess survey effort and control for its effect. We do, however, have objective information on which regions were generally better and worse surveyed: the western half of Europe was more thoroughly surveyed than the eastern half (Gasc et al., 1997; Araújo, 2003) and, within the former, some regions were particularly well studied, as they published (before the release of the European atlas) their own

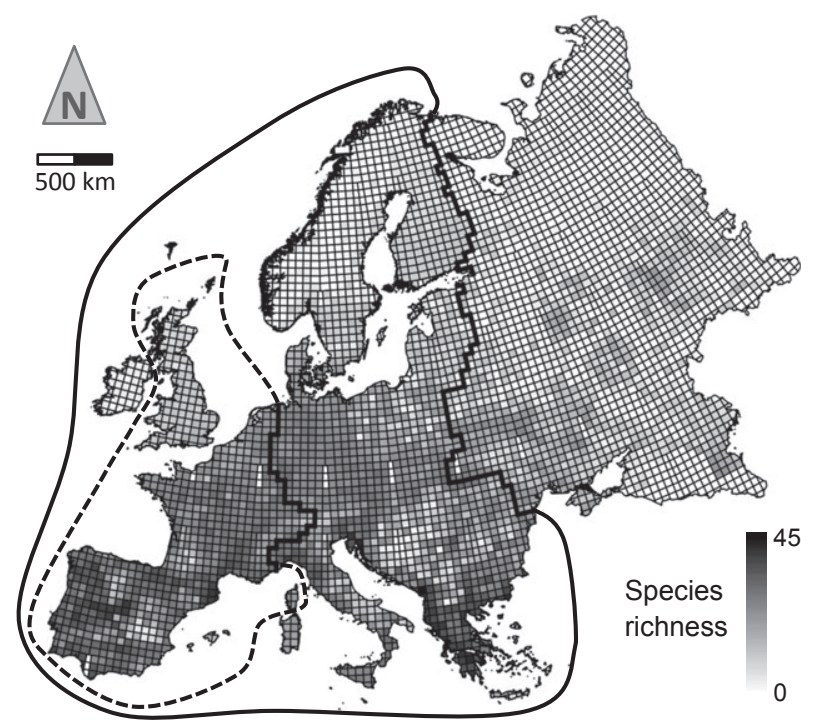

Figure 1 Species richness in UTM $50 \mathrm{~km} \times 50 \mathrm{~km}$ cells according to the European atlas of amphibians and reptiles (Gasc et al., 1997). The solid line delimits the better-surveyed western half of Europe, and the dashed line the best-surveyed regions within it. The map is in Lambert Equal Area projection (datum ETRS89). herpetological distribution atlases, generally based on $10 \mathrm{~km} \times 10 \mathrm{~km}$ UTM cells and involving well-distributed survey effort with broad national coverage (see Societas Europaea Herpetologica, 2012 for a compilation): Belgium, the Netherlands and Luxembourg (Sparreboom, 1981; Zuiderwijk \& Zuiderwijk, 1986); Switzerland (Grossenbacher, 1988); France (Castanet \& Guyetant, 1989; Delaguerre \& Cheylan, 1992); Great Britain (Arnold, 1995); Spain and Portugal (Pleguezuelos, 1997). As these national and regional atlases were based on finer-scale grids, we may assume that (at least nearly) every $50 \mathrm{~km} \times 50 \mathrm{~km}$ cell in the European atlas covering these regions included at least one smaller cell that was surveyed for herptiles.

We have thus three nested regions subjected to increasing levels of overall survey intensity: the total area covered by the European herpetological atlas; the better-surveyed western half of Europe (analysed by Araújo, 2003); and the bestsurveyed Western European countries that published a national herpetological atlas before the European one (Fig. 1). This division is qualitative rather than quantitative, but it is objective and backed up by published data (Gasc et al., 1997; Societas Europaea Herpetologica, 2012).

\section{Predictor variables}

Human population density (inhabitants $\mathrm{km}^{-2}$ ) was obtained from the LandScan ${ }^{\text {TM }}$ (2008) high-resolution global population dataset. We accounted for the possible effects of latitude and landscape diversity on the people-herptile correlations in the three different regions. Latitude is significantly associated with biodiversity across taxa and geographical regions world-wide (see Willig et al., 2003 for a review), and particularly with amphibian and reptile species richness in the western Palaearctic (Meliadou \& Troumbis, 1997). Although its biological meaning has been questioned (Hawkins \& Diniz-Filho, 2004), latitude is a surrogate for more directly relevant variables such as environmental energy and primary productivity, and it is the only one that can be objectively measured at any scale of analysis.

We analysed also the relationships of herptile species richness with potential evapotranspiration (a measure of atmospheric energy, obtained from UNEP, 2001) and actual evapotranspiration (a measure of the energy-water balance, obtained from FAO, 2009), which are the main environmental predictors of the species richness of European reptiles and amphibians, respectively (Rodríguez et al., 2005). However, these variables were measured at a coarse scale and their relationships with herptile species richness (Spearman's $\rho=0.318$, 0.490 and 0.274 for potential evapotranspiration in Europe, Western Europe and best-surveyed Europe, respectively; $\rho=0.457,0.363$ and 0.144 for actual evapotranspiration in the same three territories; $P<0.001)$ were weaker than those of latitude $(\rho=-0.572,-0.562$ and -0.530 , respectively; $P<0.001)$. Human population density also had weaker relationships with potential evapotranspiration $(\rho=0.270,0.287$ and -0.143 for Europe, Western Europe and best-surveyed 
Europe, respectively; $P<0.001)$ and with actual evapotranspiration ( $\rho=0.537,0.394$ and 0.134 , respectively; $P<0.001$ ) than with latitude $(\rho=-0.604,-0.396$ and 0.196 , respectively; $P<0.001)$. Consequently, we used latitude to control for potential confounding effects of environmental energy on the relationship between herptile species richness and human population density.

Landscape (or habitat) diversity has been less frequently tested than environmental energy as a cause of regional species-people correlations, although it may be important as well. Landscape heterogeneity naturally allows the coexistence of species with more diverse ecological requirements (e.g. Brown et al., 2011). Human beings may have settled in regions of higher landscape diversity and may sometimes have increased it (Barbosa et al., 2010b; Faeth et al., 2011; Lososová et al., 2011). Landscape diversity can thus be positively related to both biodiversity and human population, thus confounding species-people correlations. As an index of landscape diversity, we used the number of different land cover categories among water, evergreen needle-leaf forest, evergreen broadleaf forest, deciduous needle-leaf forest, deciduous broadleaf forest, mixed forest, woodland, wooded grassland, closed shrubland, open shrubland, grassland, cropland, bare ground and urban/built land (Hansen et al., 1998; Fontaneto et al., 2012) within each UTM cell.

\section{Statistical analyses}

We first performed a multiple comparison between the average species richness and the average human population density of the three regions, to assess whether biodiversity and human density both vary concomitantly with the level of survey effort. As these variables were not normally distributed, we used the nonparametric Kruskal-Wallis test for this comparison.

We then analysed the relationship between species richness and human population density in each of the three differently surveyed regions using Spearman's rank correlation tests, which are nonparametric, therefore not violating the assumption that the variables are normally distributed (as did Araújo, 2003). Given that the sample size varied between these three regions, we used Fisher's r-to-z transformation (available in the psych package of $\mathrm{R}$ ) to obtain two-tailed 95\% confidence intervals for the correlation coefficients, so that we could compare them among the regions. We also checked whether these correlations lost significance after Dutilleul's sample size adjustment for spatial autocorrelation, implemented in SAM (Spatial Analysis in Macroecology; Rangel et al., 2010). We then analysed the partial rank correlations between species richness and human population density controlling for the effects of latitude and landscape diversity.

Linear models are more powerful than rank correlations in detecting relationships between variables, as long as their statistical assumptions (such as the normal distribution of residuals) are met. We thus built also linear models relating species richness to human population density, with and without accounting for latitude and landscape diversity. For this, we used a logarithmic transformation of human population density (after adding 0.01 to all its values, to take the logarithm also for localities with zero population), which provided the closest-to-normal residuals. After checking for spatial autocorrelation in model residuals, we built simultaneous autoregressive models (available in the SAM software) to account for it. Such models incorporate spatial autocorrelation using neighbourhood matrices that specify the relationship between the residuals at each location and those at neighbouring locations (Dormann et al., 2007).

To check whether there was a threshold at which the species-people relationship changed, we performed for each region a segmented regression of species richness against logtransformed population density. Segmented (also known as broken-line, break point or piecewise) regression, available in the segmented package of $\mathrm{R}$, is a method with which the predictor variable is partitioned into intervals and a separate line segment is fit to each interval (Muggeo, 2008).

We also analysed the relationship between human population density and the presence/absence of single species, using logistic regressions. We selected species with significant parts of their range in at least the two highest levels of survey coverage in Europe (Fig. 1; Gasc et al., 1997), so that the distribution data allowed progressively reducing the focus of analysis to these regions. Among these, we analysed species that we have observed to be generally tolerant of human population (smooth newt Triturus vulgaris, common toad Bufo bufo and wall gecko Tarentola mauritanica), as well as species that are usually observed away from populated areas (alpine newt Triturus alpestris, European pond turtle Emys orbicularis and southern smooth snake Coronella girondica).

\section{RESULTS}

Herptile species richness in European $50 \mathrm{~km} \times 50 \mathrm{~km}$ UTM cells varied between 0 and 45, with the highest values recorded in the Southern European peninsulas (Fig. 1). Mean species richness increased significantly as we restricted the analysis from Europe to Western Europe to the bestsurveyed countries (Kruskal-Wallis chi-squared $=599.55$, $P<0.001$; Fig. 2a). The same occurred with human population density (Kruskal-Wallis chi-squared $=399.82$, $P<0.001$; Fig. 2b). Differences were also significant $(P<0.001)$ for pairwise comparisons between regions for both variables.

Species richness showed a positive rank correlation with human population density in the whole area covered by the European herpetological atlas and also, although less strongly, when the analysis was limited to the western half of Europe, as in Araújo (2003). However, these correlations lost significance when the number of degrees of freedom was corrected for spatial autocorrelation (Table 1). Furthermore, when analysing only the best-surveyed countries, the rank correlation between herptile richness and human density 

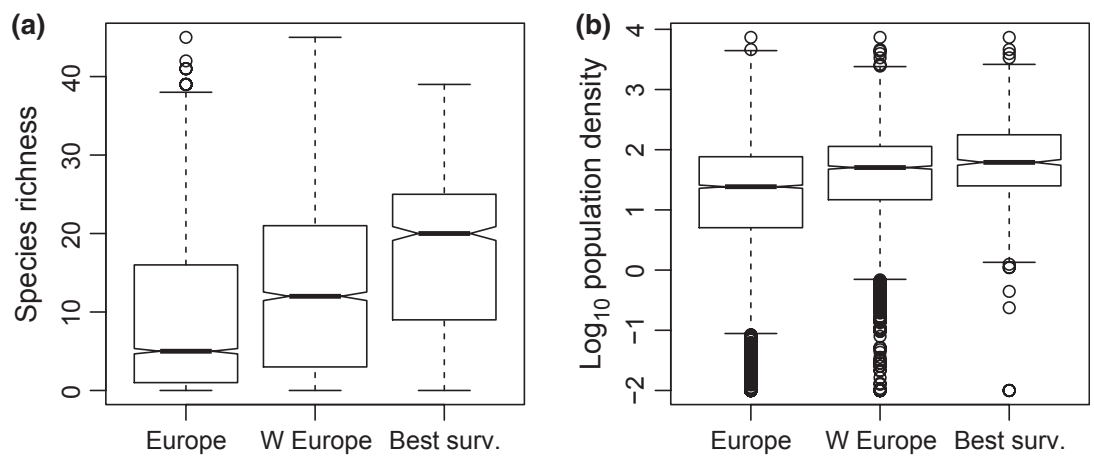

Figure 2 Box plots showing median, upper and lower quartiles, extreme values and outliers of herptile species richness (a) and log-transformed human population density (b) in UTM $50 \mathrm{~km} \times 50 \mathrm{~km}$ grid cells as we restricted the analysis from Europe $(N=4649)$ to Western Europe $(N=2615)$ to the best-surveyed regions $(N=790)$.

Table 1 Relationships between human population density and herptile species richness in Europe: Spearman's coefficients $(\rho)$ of rank correlation (with 95\% confidence intervals) and partial correlation (controlling for latitude and landscape diversity), coefficients of linear regression (B) and of simultaneous autoregressive models (SAR) in UTM $50 \mathrm{~km} \times 50 \mathrm{~km}$ cells, within three nested regions of increasing survey coverage

\begin{tabular}{|c|c|c|c|}
\hline & Europe & Western Europe & Best surveyed \\
\hline Rank correlation & $\rho=0.58, N=4649, P<0.001$ & $\rho=0.41, N=2615, P<0.001$ & $\rho=-0.08, N=790, P=0.02$ \\
\hline Confidence intervals & $0.56,0.60$ & $0.37,0.44$ & $-0.15,-0.01$ \\
\hline Corrected for autocorrelation & $\mathrm{DF}=71.77, P=0.15$ & $\mathrm{DF}=155.18, P=0.33$ & $\mathrm{DF}=371.35, P=0.02$ \\
\hline Partial rank correlation & $\rho=0.33, N=4460, P<0.001$ & $\rho=0.22, N=2474, P<0.001$ & $\rho=0.07, N=755, P=0.04$ \\
\hline Linear regression & $R^{2}=0.26, N=4649, P<0.001$ & $R^{2}=0.18, N=2615, P<0.001$ & $R^{2}<0.01, N=790, P=0.79$ \\
\hline Intercept & $\mathrm{B}=3.18, P<0.001$ & $\mathrm{~B}=5.62, P<0.001$ & $\mathrm{~B}=17.44, P<0.001$ \\
\hline $\log _{10}$ human density & $\mathrm{B}=4.87, P<0.001$ & $\mathrm{~B}=4.97, P<0.001$ & $\mathrm{~B}=0.14, P=0.79$ \\
\hline Spatial regression (SAR) & $R^{2}=0.30, N=4649, P<0.001$ & $R^{2}=0.34, N=2615, P<0.001$ & $R^{2}=0.06, N=790, P=0.78$ \\
\hline Intercept & coeff. $=5.13, P<0.001$ & coeff. $=-3.01, P=0.04$ & coeff. $=15.02, P<0.001$ \\
\hline $\log _{10}$ human density & coeff. $=3.37, P<0.001$ & coeff. $=2.32, P<0.001$ & coeff. $=0.33, P=0.48$ \\
\hline Multiple linear regression & $R^{2}=0.47, N=4460, P<0.001$ & $R^{2}=0.51, N=2474, P<0.001$ & $R^{2}=0.47, N=755, P<0.001$ \\
\hline Intercept & $\mathrm{B}=34.70, P<0.001$ & $\mathrm{~B}=38.87, P<0.001$ & $\mathrm{~B}=47.75, P<0.001$ \\
\hline Latitude & $\mathrm{B}=-0.63, P<0.001$ & $\mathrm{~B}=-0.70, P<0.001$ & $\mathrm{~B}=-0.88, P<0.001$ \\
\hline Landscape diversity & $\mathrm{B}=1.17, P<0.001$ & $\mathrm{~B}=1.66, P<0.001$ & $\mathrm{~B}=2.05, P<0.001$ \\
\hline $\log _{10}$ human density & $\mathrm{B}=1.52, P<0.001$ & $\mathrm{~B}=1.21, P<0.001$ & $\mathrm{~B}=0.65, P=0.12$ \\
\hline Multiple SAR & $R^{2}=0.50, N=4460, P<0.001$ & $R^{2}=0.62, N=2474, P<0.001$ & $R^{2}=0.47, N=755, P<0.001$ \\
\hline Intercept & coeff. $=32.54, P<0.001$ & coeff. $=30.28, P<0.001$ & coeff. $=44.65, P<0.001$ \\
\hline Latitude & coeff. $=-0.58, P<0.001$ & coeff. $=-0.70, P<0.001$ & coeff. $=-0.83, P<0.001$ \\
\hline Landscape diversity & coeff. $=1.09, P<0.001$ & coeff. $=1.39, P<0.001$ & coeff. $=1.97, P<0.001$ \\
\hline $\log _{10}$ human density & coeff. $=1.07, P=0.023$ & coeff. $=0.55, P=0.023$ & coeff. $=0.47, P=0.28$ \\
\hline
\end{tabular}

N: sample size; $p$ : significance; $R^{2}$ : coefficient of determination.

actually became negative, although weak (Table 1; scatter plots in Fig. $3 \mathrm{a}-\mathrm{c})$. After controlling for latitude and landscape diversity, the partial rank correlation between species richness and human density weakened but remained positive for Europe and Western Europe, but nearly disappeared for the best-surveyed countries (Table 1).

Linear regressions of species richness on log-transformed human population density were significant for Europe and Western Europe, with positive relationships that accounted for 26 and $18 \%$ of the species richness variation, respectively (Table 1; Fig. 3d,e). However, for the best-surveyed countries, the regression was not significant (Table 1; Fig. 3f). When including latitude and landscape diversity in the linear regressions, the models were significant at all survey coverage levels and accounted for $47-51 \%$ of the variation (Table 1 ). Latitude and landscape diversity always had a significant effect, with species richness expectably decreasing towards the North Pole and increasing with landscape diversity at all levels of survey effort. In contrast, the effect of human population density on species richness was again significant in Europe and Western Europe, but not in the best-surveyed countries (Table 1).

Autoregressive models, accounting for the spatial autocorrelation that was present in the linear models, explained a generally higher proportion of the species richness variation than non-spatial regression models. Nevertheless, the results were otherwise similar: whether or not including latitude and landscape diversity, the effect of human density was significant in Europe and in Western Europe, but not in the best-surveyed countries (Table 1).

Segmented regressions of species richness on logtransformed human population density accounted for $29 \%$ 

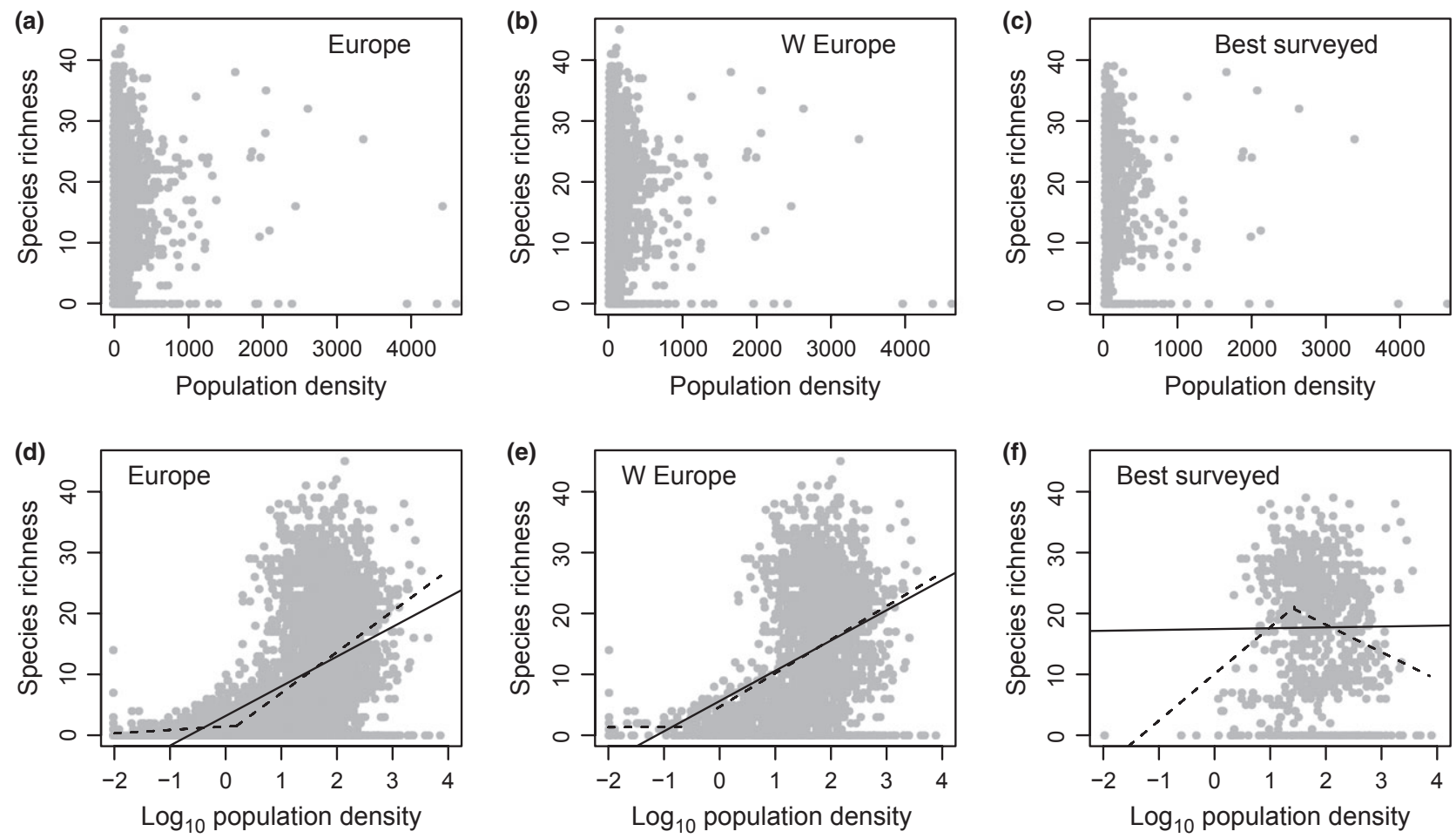

Figure 3 Scatter plots of herptile species richness against raw $(\mathrm{a}-\mathrm{c})$ and $\log$-transformed $(\mathrm{d}-\mathrm{f})$ human population density in UTM $50 \mathrm{~km} \times 50 \mathrm{~km}$ grid cells of Europe $(N=4649)$, Western Europe $(N=2615)$ and the best-surveyed regions $(N=790)$, with the fitted linear regression (solid) and segmented regression (dashed) lines.

and $19 \%$ of the variation in Europe and Western Europe, respectively. The fitted lines suggested that, in these regions, species richness barely changes with human density at very low values of the latter, with a threshold at 0.20 (c. 1.6 inhabitants $\mathrm{km}^{-2}$ ) for Europe and at -0.60 (c. 0.3 inhabitants $\mathrm{km}^{-2}$ ) for Western Europe at which a positive speciespeople relationship becomes apparent (Fig. 3d,e). For the best-surveyed region, segmented regression suggested a unimodal (hump-shaped) relationship, with species richness increasing with log-transformed population density up to a threshold of 1.43 (c. 27.2 inhabitants $\mathrm{km}^{-2}$ ), from which the relationship became negative (Fig. 3f). However, this segmented model accounted for only $8 \%$ of the variation in species richness in the best-surveyed countries. Likewise, a second-degree polynomial fit $[$ species richness $=14.23+$ $6.40 * \log _{10}$ (population density) $-2.17 * \log _{10}$ (population density $)^{2}$ ] was significant $(P<0.001)$, but accounted for even less $(6 \%)$ of the variation in species richness.

Logistic regressions of single species' presence/absence patterns on human population density revealed similar relationships. Except for the smooth newt, whose high degree of synanthropy is well known (Gasc et al., 1997) and which was positively related to human density at all survey effort levels, all other analysed species - human-avoiding as well as human-adapted - were positively related to human density when considering Europe and Western Europe, but not when the analysis was restricted to the best-surveyed countries (Table 2).

\section{DISCUSSION}

Our results indicate that there is not a reliable direct relationship between human population density and herptile diversity in Europe. Better-surveyed European regions (Fig. 1) have not only higher records of species richness, as was expected, but also higher human population density (Fig. 2). This in itself is an indication that densely inhabited regions tend to be better-surveyed, which would suggest a possible artefactual origin for the association between people and biodiversity. Correlation and regression analyses shed additional light on this relationship: whether or not using parametric methods, including ecological covariates, accounting for spatial autocorrelation or considering thresholds in the relationship, the positive association between herptile species richness and human population density disappears in well-surveyed regions (Fig. 3; Table 1). A possible explanation is that, in worse-surveyed regions, the scarcer survey efforts tend to concentrate near human settlements, while less accessible areas, which may be highly diverse as well, tend to be neglected under limited survey resources, thus producing artificial species-people correlations.

A similar pattern was observed when relating the distributions of single species to human population density: positive associations appear in Europe and also in Western Europe, not only for human-adapted species, but also for species observed to avoid populated areas. However, these associations generally disappear when the analysis is focused on the 
Table 2 Relationships between human population density and the presence/absence of six herptile species (the first three human-adapted and the last three human-avoiding) within three nested areas of increasing survey coverage in Europe

\begin{tabular}{|c|c|c|c|}
\hline & Europe & Western Europe & Best surveyed \\
\hline \multicolumn{4}{|l|}{ Smooth newt } \\
\hline Intercept & $\mathrm{B}=0.37, P<0.001$ & $\mathrm{~B}=0.48, P<0.001$ & $\mathrm{~B}=0.30, P<0.001$ \\
\hline Human density & $\mathrm{B}=0.00049, P<0.001$ & $\mathrm{~B}=0.00035, P<0.001$ & $\mathrm{~B}=0.00040, P<0.001$ \\
\hline \multicolumn{4}{|l|}{ Common toad } \\
\hline Intercept & $\mathrm{B}=0.54, P<0.001$ & $\mathrm{~B}=0.72, P<0.001$ & $\mathrm{~B}=0.94, P<0.001$ \\
\hline Human density & $\mathrm{B}=0.00047, P<0.001$ & $\mathrm{~B}=0.00029, P<0.001$ & $\mathrm{~B}=0.000012, P=0.70$ \\
\hline \multicolumn{4}{|l|}{ Wall gecko } \\
\hline Intercept & $\mathrm{B}=0.061, P<0.001$ & $\mathrm{~B}=0.10, P<0.001$ & $\mathrm{~B}=0.26, P<0.001$ \\
\hline Human density & $\mathrm{B}=0.00019, P<0.001$ & $\mathrm{~B}=0.00017, P<0.001$ & $\mathrm{~B}=-0.000017, P=0.75$ \\
\hline \multicolumn{4}{|l|}{ Alpine newt } \\
\hline Intercept & $\mathrm{B}=0.13, P<0.001$ & $\mathrm{~B}=0.21, P<0.001$ & $\mathrm{~B}=0.29, P<0.001$ \\
\hline Human density & $\mathrm{B}=0.00033, P<0.001$ & $\mathrm{~B}=0.00029, P<0.001$ & $\mathrm{~B}=0.00011, P=0.06$ \\
\hline \multicolumn{4}{|c|}{ European pond turtle } \\
\hline Intercept & $\mathrm{B}=0.19, P<0.001$ & $\mathrm{~B}=0.27, P<0.001$ & $\mathrm{~B}=0.29, P<0.001$ \\
\hline Human density & $\mathrm{B}=0.00034, P<0.001$ & $\mathrm{~B}=0.00028, P<0.001$ & $\mathrm{~B}=0.000044, P=0.45$ \\
\hline \multicolumn{4}{|c|}{ Southern smooth snake } \\
\hline Intercept & $\mathrm{B}=0.066, P<0.001$ & $\mathrm{~B}=0.11, P<0.001$ & $\mathrm{~B}=0.36, P<0.001$ \\
\hline Human density & $\mathrm{B}=0.00013, P<0.001$ & $\mathrm{~B}=0.00010, P=0.0015$ & $\mathrm{~B}=-0.000078, P=0.20$ \\
\hline
\end{tabular}

B: logistic regression coefficients; $p$ : significance.

best-surveyed regions (Table 2). A positive relationship between human density and the presence of human-adapted species might not be surprising, given that such species tolerate and may even profit from living near or within human settlements. However, the fact that even species that are known to avoid human proximity showed a positive correlation with human density across Europe and Western Europe (which disappeared in the best-surveyed regions) corroborates the existence of survey bias, which is likely to have an effect on the correlation between human density and biodiversity.

Controlling for latitude and landscape diversity in the analyses showed that, while herptile species richness is clearly related to both these variables at all levels of survey coverage (in accordance with numerous previous studies: see, for example, Meliadou \& Troumbis, 1997; Willig et al., 2003), the same does not occur with human population density, whose effect disappears when we focus on well-surveyed areas (Table 1). Controlling for spatial autocorrelation allowed us to account for more of the variation in species richness (possibly due to spatially autocorrelated variables or processes that were not explicitly included) and to estimate the regression parameters more correctly, but did not change the essential result that, unlike latitude and landscape diversity, human density has no effect on species richness in wellsurveyed regions (Table 1). This is another indication that the correlation between species richness and human population may be, at least in part, artefactual.

We remark that our comparisons of species-people correlations among differently surveyed areas implied analysis at different scales of spatial extent, but not different scales of resolution (grain). To sort out factors related to species diversity, it is necessary to hold the resolution constant; holding the extent constant is not so crucial, although it can be insightful to examine how the form of a relationship changes with the spatial extent (Whittaker \& Heegaard, 2003). Changes in spatial resolution have often led to changes in species-people correlations as well, with most species being positively associated with humans at broad but not at finer scales (e.g. Pautasso, 2007 and references therein; see, however, Barbosa et al., 2010b for an inverse case). What we have shown here is that, at the same scale of resolution, herptile species-people correlations in Europe disappear as we restrict the analysis to better-surveyed areas.

While our results suggested nonlinear responses (Fig. 3d,e), the actual relationship between biodiversity and human population is probably more complex than can be gathered from the analysed data. Future research could attempt to unravel the causal relationships among biodiversity, human population, environmental energy, landscape diversity and survey effort, using more powerful tools such as, for example, structural equation modelling. However, such analyses would require thorough datasets, with reliable and quantitative information on the intensity of survey effort associated with each species record. While there might be ecological reasons why wild species share similar regions with humans and why these regions might be better-surveyed, the available evidence suggests that the species-people correlation in Europe, at least as far as herptiles are concerned, is an artefact of survey bias.

Our results do not deny the observation that many densely populated regions are also highly biodiverse, with a range of conservation implications (Balmford et al., 2001; Araújo, 2003; Luck et al., 2004; Pautasso, 2007; Barbosa et al., 2010a,b). However, our findings do show that more densely populated 
regions are not necessarily more biodiverse, but mainly better surveyed, than more remote regions. Our findings thus challenge those of Araújo (2003) for the same study area, as well as those of similar studies elsewhere (e.g. Balmford et al., 2001). More importantly, they point to the crucial importance of addressing sampling artefacts whenever possible in biodiversity analyses (see also Ribas et al., 2007; Barbosa et al., 2010b; Cantarello et al., 2010; Fontaneto et al., 2012) or, in any case, of being well aware of and always acknowledging a possible survey bias.

Data quality is determinant in the analysis of spatial trends in species distribution and diversity (Hortal et al., 2007; Lobo, 2008; Milanovich et al., 2012). An adequate identification of conservation conflicts therefore requires more rigorous assessments of the effect of survey effort on biodiversity data. Even when no explicit information is available on the amount of survey effort associated with each biodiversity record, it may be possible to at least broadly distinguish better- from worse-surveyed regions, as we did here based on published data (Gasc et al., 1997; Societas Europaea Herpetologica, 2012), and thus to check whether an observed relationship is robust. Conservation biogeography would profit from better awareness and consideration of the effects of survey effort on species' diversity and distribution analyses.

Our results also highlight the value of recording survey effort along with biodiversity data, as well as the need for better biodiversity surveys in scarcely populated regions, especially if these are to be included in biogeographical analyses. Survey effort not only appears as a key factor in biogeographical research in general (Barbosa et al., 2005; Ribas et al., 2007; Fontaneto et al., 2012), but can play a particularly important role in species-people correlations (e.g. Barbosa et al., 2010b; Fontaneto et al., 2012), even for relatively wellstudied groups such as European amphibians and reptiles.

\section{ACKNOWLEDGEMENTS}

This study was presented as a poster at the meeting of the International Biogeography Society in Miami, 2013. We thank the Societas Europaea Herpetologica, the national atlas representatives and all fieldworkers and researchers who contributed with their distribution records. Neftalí Sillero, Raquel Ribeiro, David Romero and Raimundo Real provided useful information. François Guilhaumon helped with parts of the R code. A.M.B. is supported by a postdoctoral fellowship (SFRH/BPD/40387/2007) from Fundação para a Ciência e a Tecnologia, Portugal, co-financed by the European Social Fund. Support was also received from the Integrated Programme of IC\&DT No. 1/SAESCTN/ALENT-07-0224FEDER-001755.

\section{REFERENCES}

Araújo, M.B. (2003) The coincidence of people and biodiversity in Europe. Global Ecology and Biogeography, 12, 5-12.
Arnold, H.R. (1995) Atlas of amphibians and reptiles in Britain. HMSO, London (ITE research publication no.10).

Balmford, A., Moore, J.L., Brooks, T., Burgess, N., Hansen, L.A., Williams, P. \& Rahbek, C. (2001) Conservation conflicts across Africa. Science, 291, 2616-2619.

Barbosa, A.M., Segovia, J.M., Vargas, J.M., Torres, J., Real, R. \& Miquel, J. (2005) Predictors of red fox (Vulpes vulpes) helminth parasite diversity in the provinces of Spain. Wildlife Biology in Practice, 1, 3-14.

Barbosa, A.M., Fontaneto, D., Marini, L. \& Pautasso, M. (2010a) Positive regional species-people correlations: a sampling artefact or a key issue for sustainable development? Animal Conservation, 13, 446-447.

Barbosa, A.M., Fontaneto, D., Marini, L. \& Pautasso, M. (2010b) Is the human population a large-scale indicator of the species richness of ground beetles? Animal Conservation, 13, 432-441.

Bombi, P., D’Amen, M., Salvi, D., Bologna, M.A., Marcone, F., Maggio, C. \& Canu, A. (2012) Amphibians conservation in Italy: the contribution of the WWF Oases network. Italian Journal of Zoology, 79, 287-295.

Brown, G.W., Dorrough, J.W. \& Ramsey, D.S.L. (2011) Landscape and local influences on patterns of reptile occurrence in grazed temperate woodlands of southern Australia. Landscape and Urban Planning, 103, 277-288.

Cantarello, E., Steck, C.E., Fontana, P., Fontaneto, D., Marini, L. \& Pautasso, M. (2010) A multi-scale study of Orthoptera species richness and human population size controlling for sampling effort. Naturwissenschaften, 97, 265-271.

Castanet, J. \& Guyetant, R. (1989) Atlas de répartition des amphibiens et reptiles de France. Société Herpétologique de France, Paris.

Ceríaco, L.M.P. (2012) Human attitudes towards herpetofauna: the influence of folklore and negative values on the conservation of amphibians and reptiles in Portugal. Journal of Ethnobiology and Ethnomedicine, 8, 8.

Davies, Z.G., Fuller, R.A., Loram, A., Irvine, K.N., Sims, V. \& Gaston, K.J. (2009) A national scale inventory of resource provision for biodiversity within domestic gardens. Biological Conservation, 142, 761-771.

Delaguerre, M. \& Cheylan, M. (1992) Atlas de répartition des Batraciens et reptiles de Corse. Parc Naturel Régional de la Corse, E. P. H. E., Ajaccio.

Diniz-Filho, J.A.F., Bini, L.M. \& Hawkins, B.A. (2003) Spatial autocorrelation and red herrings in geographical ecology. Global Ecology and Biogeography, 12, 53-64.

Dormann, C.F., McPherson, J.M., Araújo, M.B., Bivand, R., Bolliger, J., Carl, G., Davies, R.G., Hirzel, A., Jetz, W., Kissling, W.D., Kühn, I., Ohlemüller, R., Peres-Neto, P.R., Reineking, B., Schröder, B., Schurr, F.M. \& Wilson, R. (2007) Methods to account for spatial autocorrelation in the analysis of species distributional data: a review. Ecography, 30, 609-628.

Ellis, E.C., Antill, E.C. \& Kreft, H. (2012) All is not loss: plant biodiversity in the anthropocene. PLoS ONE, 7, e30535. 
Faeth, S.H., Bang, C. \& Saari, S. (2011) Urban biodiversity: patterns and mechanisms. Annals of the New York Academy of Sciences, 1223, 69-81.

FAO (2009) Global map of yearly actual evapotranspiration 5 arc-minutes. Available at: http://www.fao.org/geonetwork/ srv/en/metadata.show?id=37233 (accessed 8 June 2012).

Ficetola, G.F., Bonardi, A., Sindaco, R. \& Padoa-Schioppa, E. (2013) Estimating patterns of reptile biodiversity in remote regions. Journal of Biogeography, 40, 1202-1211.

Fjeldså, J. (2007) The relationship between biodiversity and population centres: the high Andes region as an example. Biodiversity and Conservation, 16, 2739-2751.

Fontaneto, D., Barbosa, A.M., Segers, H. \& Pautasso, M. (2012) The 'rotiferologist' effect and other global correlates of species richness in monogonont rotifers. Ecography, 35, 174-182.

Gasc, J.P., Cabela, A., Crnobrnja-Isailovic, J., Dolmen, D., Grossenbacher, K., Haffner, P., Lescure, J., Martens, H., Martínez Rica, J.P., Maurin, H., Oliveira, M.E., Sofianidou, T.S., Veith, M. \& Zuiderwijk, A. (eds) (1997) Atlas of amphibians and reptiles in Europe. Collection Patrimoines Naturels, 29. Societas Europaea Herpetologica, Muséum National d'Histoire Naturelle \& Service du Patrimoine Naturel, Paris.

GRASS Development Team (2010) Geographic resources analysis support system. Open Source Geospatial Foundation. Available at: http://grass.osgeo.org (accessed 10 January 2009).

Grossenbacher, K. (1988) Atlas de distribution des amphibiens de Suisse. Documenta Faunistica Helvetiae 8.

Hansen, M., DeFries, R., Townshend, J.R.G. \& Sohlberg, R. (1998) UMD global land cover classification, $1 \mathrm{~km}$, 19811994. Version 1.0. Department of Geography, University of Maryland, College Park, MD. Available at: www.landcover. org/data/landcover (accessed 10 January 2009).

Hawkins, B.A. \& Diniz-Filho, J.A.F. (2004) 'Latitude' and geographic patterns in species richness. Ecography, 27, 268-272.

Herrmann, D.L., Pearse, I.S. \& Baty, J.H. (2012) Drivers of specialist herbivore diversity across 10 cities. Landscape and Urban Planning, 108, 123-130.

Hortal, J., Lobo, J.M. \& Jiménez-Valverde, A. (2007) Limitations of biodiversity databases: case study on seed-plant diversity in Tenerife, Canary Islands. Conservation Biology, 21, 853-863.

Johnson, P.T.J., Hoverman, J.T., McKenzie, V.J., Blaustein, A.R. \& Richgels, K.L.D. (2013) Urbanization and wetland communities: applying metacommunity theory to understand the local and landscape effects. Journal of Applied Ecology, 50, 34-42.

Kühn, I., Brandl, R. \& Klotz, S. (2004) The flora of German cities is naturally species rich. Evolutionary Ecology Research, 6, 749-764.

Kummu, M., de Moel, H., Ward, P.J. \& Varis, O. (2011) How close do we live to water? A global analysis of population distance to freshwater bodies. PLoS ONE, 6, e20578.

LandScan $^{\mathrm{TM}}$ (2008) High Resolution Global Population Data Set. Copyrighted by UT-Battelle, LLC, operator of Oak
Ridge National Laboratory under Contract No. DE-AC05-00OR22725 with the United States Department of Energy. Available at: http://www.ornl.gov/sci/landscan/ landscan_documentation.shtml (accessed 4 November 2010).

Lobo, J.M. (2008) More complex distribution models or more representative data? Biodiversity Informatics, 5, 14-19.

Lososová, Z., Horsák, M., Chytrý, M., Čejka, T., Danihelka, J., Fajmon, K., Hájek, O., Juřičková, L., Kintrová, K., Láníková, D., Otýpková, Z., Řehořek, V. \& Tichý, L. (2011) Diversity of Central European urban biota: effects of human-made habitat types on plants and land snails. Journal of Biogeography, 38, 1152-1163.

Luck, G.W., Ricketts, T.H., Daily, G.C. \& Imhoff, M. (2004) Alleviating spatial conflict between people and biodiversity. Proceedings of the National Academy of Sciences USA, 101, 182-186.

Luck, G.W., Smallbone, L., McDonald, S. \& Duffy, D. (2010) What drives the positive correlation between human population density and bird species richness in Australia? Global Ecology and Biogeography, 19, 673-683.

Marini, L., Battisti, A., Bona, E., Federici, G., Martini, F., Pautasso, M. \& Hulme, P.E. (2012) Alien and native plant life-forms respond differently to human and climate pressures. Global Ecology and Biogeography, 21, 534-544.

McCauley, L.A., Jenkins, D.G. \& Quintana-Ascencio, P.F. (2013) Isolated wetland loss and degradation over two decades in an increasingly urbanized landscape. Wetlands, 33, 117-127.

Meliadou, A. \& Troumbis, A.Y. (1997) Aspects of heterogeneity in the distribution of diversity of the European herpetofauna. Acta Oecologica, 18, 393-412.

Milanovich, J.R., Peterman, W.E., Barrett, K. \& Hopton, M.E. (2012) Do species distribution models predict species richness in urban and natural green spaces? A case study using amphibians. Landscape and Urban Planning, 107, 409-418.

Moreno-Rueda, G. \& Pizarro, M. (2007) The relative influence of climate, environmental heterogeneity, and human population on the distribution of vertebrate species richness in south-eastern Spain. Acta Oecologica, 32, 50-58.

Moreno-Rueda, G. \& Pizarro, M. (2009) Relative influence of habitat heterogeneity, climate, human disturbance, and spatial structure on vertebrate species richness in Spain. Ecological Research, 24, 335-344.

Muggeo, V.M.R. (2008) Segmented: an R package to fit regression models with broken-line relationships. $R$ News, 8, 20-25.

Murrieta-Galindo, R., López-Barrera, F., González-Romero, A. \& Parra-Olea, G. (2013) Matrix and habitat quality in a montane cloud-forest landscape: amphibians in coffee plantations in central Veracruz, Mexico. Wildlife Research, 40, 25-35.

Pautasso, M. (2007) Scale dependence of the correlation between human population presence and vertebrate and plant species richness. Ecology Letters, 10, 16-24. 
Pautasso, M. \& Fontaneto, D. (2008) A test of the speciespeople correlation for stream macro-invertebrates in European countries. Ecological Applications, 18, 1842-1849.

Pautasso, M. \& McKinney, M.L. (2007) The botanist effect revisited: plant species richness, county area and human population size in the US. Conservation Biology, 21, 1333-1340.

Pautasso, M., Böhning-Gaese, K., Clergeau, P., Cueto, V.R., Dinetti, M., Fernández-Juricic, E., Kaisanlahti-Jokimäki, M.-L., Jokimäki, J., McKinney, M.L., Sodhi, N.S., Storch, D., Tomialojc, L., Weisberg, P.J., Woinarski, J., Fuller, R.A. \& Cantarello, E. (2011) Global macroecology of bird assemblages in urbanized and semi-natural ecosystems. Global Ecology and Biogeography, 20, 426-436.

Pecher, C., Fritz, S., Marini, L., Fontaneto, D. \& Pautasso, M. (2010) Scale-dependence of the correlation between human population and the species richness of stream macroinvertebrates. Basic and Applied Ecology, 11, 272-280.

Pleguezuelos, J.M. (ed) (1997) Distribución y biogeografía de los anfibios y reptiles en España y Portugal. Universidad de Granada and AHE, Granada.

Quantum GIS Development Team (2010) Quantum GIS Geographic Information System. Open Source Geospatial Foundation. Available at: http://qgis.osgeo.org (accessed 10 January 2009).

R Development Core Team (2012) R: a language and environment for statistical computing. $\mathrm{R}$ Foundation for Statistical Computing. Available at: http://www.r-project.org (accessed 10 January 2012).

Rangel, T.F., Diniz-Filho, J.A.F. \& Bini, L.M. (2010) SAM: a comprehensive application for Spatial Analysis in Macroecology. Ecography, 33, 46-50.

Ribas, A., Barbosa, A.M., Casanova, J.C., Real, R., Feliu, C. \& Vargas, J.M. (2007) Geographical patterns of the species richness of helminth parasites of moles (Talpa spp.) in Spain: separating the effect of survey effort from those of other conditioning factors. Vie et Milieu, 57, 45-52.

Ribeiro, R., Torres, J., Carretero, M.A., Sillero, N. \& Llorente, G.A. (2010) Unsuspected richness near home: new herpetological records in Porto Metropolitan Area (NW Portugal). Boletín de la Asociación Herpetológica Española, 21, 27-33.

Rodríguez, M.A., Belmontes, J.A. \& Hawkins, B.A. (2005) Energy, water and large-scale patterns of reptile and amphibian species richness in Europe. Acta Oecologica, 28, 65-70.

Sastre, P., Roca, P., Lobo, J.M. \& EDIT co-workers (2009) A Geoplatform for improving accessibility to environmental cartography. Journal of Biogeography, 36, 568.

Scheffers, B.R. \& Paszkowski, C.A. (2013) Amphibian use of urban stormwater wetlands: the role of natural habitat features. Landscape and Urban Planning, 113, 139-149.

Sinervo, B., Méndez-de-la-Cruz, F., Miles, D.B. et al. (2010) Erosion of lizard diversity by climate change and altered thermal niches. Science, 328, 894-899.

Societas Europaea Herpetologica (2012) Books: other relevant books. Available at: http://www.seh-herpetology.org/books/ otherbooks.htm (accessed 10 February 2012).
Sparreboom, M. (ed) (1981) De amfibiën en reptielen van Nederland, Belgï en Luxembourg. A.A. Balkema, Rotterdam.

Steck, C.E. \& Pautasso, M. (2008) Human population, grasshopper and plant species richness in European countries. Acta Oecologica, 34, 303-310.

Stuart, S.N., Chanson, J.S., Cox, N.A., Young, B.E., Rodrigues, A.S.L., Fischman, D.L. \& Waller, R.W. (2004) Status and trends of amphibian declines and extinctions worldwide. Science, 306, 1783-1786.

UNEP (2001) Potential Evapotranspiration [1994]. Environmental Data Explorer, United Nations Environment Programme. Available at: http://geodata.grid.unep.ch (accessed 12 January 2010).

Vačkáŕ, D., Chobot, K. \& Orlitová, E. (2012) Spatial relationship between human population density, land use intensity and biodiversity in the Czech Republic. Landscape Ecology, 27, 1279-1290.

Whittaker, R.J. \& Heegaard, E. (2003) What is the observed relationship between species richness and productivity? Comment. Ecology, 84, 3384-3390.

Willig, M.R., Kaufman, D.M. \& Stevens, R.D. (2003) Latitudinal gradients of biodiversity: pattern, process, scale, and synthesis. Annual Review of Ecology, Evolution, and Systematics, 34, 273-309.

Zuiderwijk, W. \& Zuiderwijk, A. (1986) Atlas van de Nederlandse amfibiën en reptielen en hun bedreiging. K.N.N.V., Hoogwoud.

\section{BIOSKETCHES}

A. Márcia Barbosa is a postdoctoral fellow jointly hosted by Imperial College London (UK) and the Research Centre in Biodiversity and Genetic Resources (CIBIO) at the University of Évora (Portugal). Her research interests include biogeography, macroecology, distribution modelling, biodiversity patterns and conservation.

Marco Pautasso is a postdoc at the Centre of Functional and Evolutionary Ecology (CEFE) in Montpellier (France). His main interests are conservation biogeography, landscape pathology, network epidemiology and scientometrics.

Diogo Figueiredo is Full Professor at the University of Évora. Among his wide range of interests are ecology, entomology, the conservation of invertebrates and the management of wildlife. He is currently developing several projects in Africa in the areas of conservation and environment.

Author contributions: A.M.B. conceived the idea, gathered and analysed the data, and led the writing. M.P. and D.F. proposed additional analyses and improved writing, interpretation and presentation.

Editor: Dr. Ingolf Kühn 